\title{
Attaining and Maintaining Preparation: A Comparison of Attention in Hyperactive, Normal, and Disturbed Control Children
}

\author{
R. Schachar, ${ }^{1,2}$ G. Logan, ${ }^{3}$ R. Wachsmuth, ${ }^{1}$ and D. Chajczyk ${ }^{1}$
}

The hypothesis that hyperactive children have a deficit in sustained attention was investigated. Eighteen children who had attention deficit disorder with hyperactivity $(A D D H)$, aged 7 to 11 years, were compared with children who had conduct disorder $(n=15)$, mixed conduct disorder and ADDH $(n=26)$, emotional disorder $(n=18)$, or learning disability $(n=$ $22)$, and with normal controls $(n=15)$. The subjects were tested on three versions of the Continuous Performance Task. Sustained attention was assessed from performance with increasing time on task and from ability to prepare attention in response to a warning. Performance of all subjects deteriorated with increasing time and improved with the opportunity to prepare attention. Hyperactive subjects were not more adversely affected by increasing time, nor did they benefit less than controls from the opportunity to prepare attention. Data reanalysis after rediagnosis according to ICD-9 criteria did not change the results. This study did not confirm the hypothesis that hyperactive children have a unique sustained attention deficit.

Manuscript received in final form December 7, 1987.

This research was supported by a grant from the Ontario Mental Health, Ruth Schwartz, and Canadian Psychiatric Research Foundations. The manuscript was prepared with the assistance of the Medical Publications Department, The Hospital for Sick Children, Toronto. ${ }^{1}$ Department of Psychiatry, The Hospital for Sick Children, Toronto, Ontario, Canada M5G 1 X8.

${ }^{2}$ Address all correspondence to Dr. Russell Schachar, The Hospital for Sick Children, 555 University Avenue, Toronto, Ontario, Canada M5G 1 X8.

${ }^{3}$ Department of Psychology, University of Illinois at Urbana-Champaign, Illinois. 


\section{INTRODUCTION}

Considerable clinical and experimental evidence suggests that hyperactive children have a deficient ability to attend during academic and social tasks (Douglas, 1983). The strongest support for the attention-deficit hypothesis comes from research into the performance of hyperactive children on attention-demanding laboratory tasks. Compared with normal children, they are more distractible (e.g., Ceci \& Tishman, 1984) and impulsive (e.g., Campbell, 1974; Firestone \& Martin, 1979) and, in particular, less able to sustain attention (e.g., Cohen \& Douglas, 1972; Sykes, Douglas, \& Morgenstern, 1973).

Sustained attention involves the ability to remain vigilant over long periods of time (as measured through the effect of time on task) and the ability to prepare and maintain readiness for response (as measured through the effect of warning signals on reaction time). The ability to sustain attention has been studied extensively using various versions of the Continuous Performance Task (CPT; Rosvold, Mirsky, Sarason, Bransome, \& Beck, 1956). In the CPT, children must respond to a specific target letter or pattern of letters presented within a series of nontarget letters. Generally, hyperactive children perform less well than normal controls. They make more false positive and fewer correct responses and have slower mean reaction times for correct responses (Sykes, Douglas, Weiss, \& Minde, 1971; Sykes et al., 1973; Michael, Klorman, Salzman, Borgstedt, \& Dainer, 1981; Nuechterlein, 1983; Rapoport et al., 1980).

However, reported differences in performance between hyperactive and normal groups on any one version of the CPT, evident as a main effect of diagnostic group, are not necessarily attributable to inability to sustan attention. The methods used in the studies to date do not permit the rejection of alternative explanations for poor performance (e.g., deficits in coordination, vision, understanding, or cooperation) that could affect the overall level of performance on an attention-demanding task.

Instead, experimental factors that are known to affect subjects' ability to sustain attention must be manipulated. Evaluation of the effects of these factors on performance should provide a measure of one's ability to attend. Differences in attention would be evident in an interaction between the level of attentional demand associated with these factors and diagnostic group, rather than in group differences for overall level of performance. If inattentive subjects such as hyperactive children have a deficit in attention, they should be affected differently by these experimental manipulations than are normal, attentive children.

In CPT studies, time on task has been the most commonly investigated experimental factor (Sykes et al., 1973; Michael et al., 1981). Although the various versions of the CPT that have been used constitute 
another experimental manipulation, previous research has not exploited the differences among these versions to clarify intergroup differences in sustained attention (e.g., Michael et al., 1981).

There are three basic versions of the CPT, which we call A, AX, and AA. In each version, subjects are instructed to respond to the presence of a target letter (e.g., A) or pattern of letters (e.g., an X immediately following an $\mathrm{A}$ ) and to refrain from responding to nontarget letters. These versions differ in several ways that might affect attention and, consequently, speed and accuracy of performance. For example, they vary in the presence of a letter warning of a subsequent target. In the presence of this warning, subjects have the opportunity to anticipate a target, mobilize attention, and process the target more quickly and accurately. However, the presence of a warning may result in a greater number of impulsive responses (Posner, Klein, Summers, \& Buggie, 1973).

Also, the similarity between the warning and target letters varies in those versions that provide a warning (e.g., AX and AA). When the warning and target letters are identical, the subject may become confused about which letter is the target and which is the warning, producing a difference in the rate of impulsive response to the warning compared with all other nontarget letters.

If hyperactive children are relatively poor at sustaining attention over time, there should be an interaction between diagnostic group and time on task. Response time and accuracy should deteriorate more rapidly in hyperactive than in nonhyperactive children as time on task increases. If they are relatively poor at preparing for an impending target, there should be an interaction between diagnostic group and version of the CPT. Hyperactive children should show smaller differences between CPT versions than do nonhyperactive children. Furthermore, if hyperactive children are more impulsive, they should respond to a nontarget $\mathrm{A}$ in the $\mathrm{AA}$ and $\mathrm{AX}$ versions more often than to other nontarget letters and make more false alarms to warning letters that are similar to target letters than do nonhyperactive children. Again, this would be evident as an interaction between diagnostic group, version of the CPT, and type of false alarm.

Two studies examined the interaction between time on task and diagnosis with contradictory results. Sykes et al. (1973) found that hyperactive children detected fewer targets and made more errors with time on the AX version of the CPT, whereas Michael et al. (1981) reported no greater deterioration with time on task in hyperactive children than in controls. Two studies tested subjects on more than one CPT version (Sykes et al., 1971; Michael et al., 1981) and found that more targets were correctly detected in the $\mathrm{A}$ than the $\mathrm{AX}$ version. The failure to observe the predicted differences among versions might have resulted from the absence of any measure of response time. While preparation improves reaction time con- 
sistently and reliably, it may or may not improve accuracy (Posner et al., 1973; Thomas, 1974). The hypothesis that hyperactive children are uniquely deficient in the ability to sustain attention can be tested only by an experiment in which demand for sustained attention is manipulated and both speed and accuracy are measured.

Two other methodological issues are important in determining whether an attention deficit is correlated with hyperactivity rather than some other aspect of disturbance (e.g., conduct disorder). Previous studies have focused on differences between hyperactive children and normal controls without attempting to control for factors associated with hyperactivity, such as learning, emotional, or conduct disorders. Therefore, hyperactive children must be distinguished from those with conduct disorders by careful assessment, and they must be compared with children who have conduct, emotional, or learning disorders to determine whether the attention deficit is unique to their condition (Werry, Reeves, \& Elkind, 1987). The following study was conducted to test the hypothesis that hyperactive children have a unique deficit in the ability to sustain attention over time and to prepare for the presentation of a target.

\section{METHOD}

\section{Subjects}

The subjects were 99 boys, 7 to 11 years old, who had learning or behavior problems and were referred to a child psychiatric outpatient department, and 15 normal male volunteers whose families answered an advertisement in the newsletter of a parent-teacher association. Children who had a full-scale IQ of less than 80, evidence of a neurological disorder such as epilepsy, or a history or evidence of psychosis or severe developmental delay, and those who were currently on medication, were excluded. Only boys were included because of the predominance of males among the population of hyperactive children (Schachar, Rutter, \& Smith, 1981). For all children, a diagnosis was based on information obtained in an interview of each child's parents, behavior ratings completed by the child's teacher, and a psychoeducational assessment.

\section{Assessment}

Information was obtained by one of two child psychiatrists from each child's parent or parents following a semistructured interview protocol. The 
protocol investigated prenatal, birth, postnatal, developmental, medical, academic, and family history, as well as child behavior and symptoms of psychopathology. The interview also reviewed the child's interactions with peers, siblings, and adults, as well as symptoms associated with affective, anxiety, and psychosomatic disorders. Special attention was paid to activity level, attentiveness, and impulsiveness in a variety of settings. For each symptom, parents were asked to describe and give a recent example of their child's behavior. The interviewer rated each symptom on the basis of severity of disability.

Interrater reliability of the parent interview was assessed by having a second psychiatrist rate audiotapes of 18 randomly selected assessments. Raters agreed on the presence or absence of $97 \%$ of symptoms (Kappa, .92). In all cases there was agreement about diagnosis.

The classroom teacher of each child completed the Rutter-B rating scale (Rutter, 1967), the abbreviated Conners teacher rating scale (Conners, 1973), and the SNAP questionnaire (W. E. Pelham, personal communication, 1981). The psychoeducational assessment consisted of four subtests from the WISC-R (block design, object assembly, similarities, and vocabulary; Wechsler, 1974), and the Wide Range Achievement Test (WRAT; Jastak \& Wilkinson, 1984). If these tests had been administered to the child within the previous year, consent to obtain results was sought and the tests were not readministered.

DSM-III Diagnosis. The symptoms of inattentiveness, impulsiveness, and overactivity from the DSM-III (American Psychiatric Association, 1980) were compared with the findings from the parental interview. A diagnosis of attention deficit disorder with hyperactivity (ADDH) was made if the child had at least three symptoms of inattentiveness, three of impulsiveness, and two of overactivity, in addition to a history of hyperactivity, impulsiveness, or inattentiveness before 6 years of age.

In keeping with DSM-III guidelines (American Psychiatric Association, 1980, p. 43), ADDH was also diagnosed if a child's teacher rated him as disturbed and significantly hyperactive. A rating of 9 or more on the Rutter-B questionnaire was taken as an indication of psychiatric disturbance (Rutter, Tizard, \& Whitmore, 1970). Hyperactivity was judged to be clinically significant in the presence of any two of the following three criteria: (1) a rating of 5 or 6 on the Rutter-B hyperactivity factor (a score obtained by $3 \%$ of 10-year-old males; Schachar et al., 1981), (2) a rating of 4 inattentive, 4 impulsive, and 3 overactive items on the SNAP questionnaire (a score obtained by $5 \%$ of 10 -year-old males; W. E. Pelham, personal communication, 1981), and (3) an abbreviated Conners score of 15 or more (a score predictive of a clinical diagnosis of hyperactivity; Goyette, Conners, \& Ulrich, 1978). 
Children were assigned to the conduct disorder (CD) group if they met DSM-III criteria for conduct disorder or oppositional disorder. Oppositional disorder was diagnosed only in the presence of severe and pervasive oppositional symptoms involving relationships with both parents or a variety of adults. CD and oppositional disorder were combined on the grounds that the two diagnoses have not been differentiated and are qualitatively similar (Werry, Methven, Fitzpatrick, \& Dixon, 1983; Anderson, Williams, McGee, \& Silva, 1987; Werry et al., 1987). Children were assigned to the ADDH + CD group if they met the criteria for both conditions. Because there is considerable doubt about the reliability of the distinction between these subcategories (Quay, 1986), a diagnosis of emotional disorder (ED) was assigned to children meeting DSM-III criteria for any of the following: separation anxiety, overanxious, affective, phobic, obsessive-compulsive, panic, or somatization disorder. Learning disability (LD) was diagnosed if the full-scale IQ was average or above and the standard score on the WRAT reading subtest was below the 25th percentile in the absence of a physical or sensory disorder (Seigel \& Heaven, 1986). By these criteria, children in the $\mathrm{CD}, \mathrm{ED}$, and LD groups were not hyperactive.

To be included as controls, children had to be free of any diagnosis.

ICD-9 Diagnosis. Each child was reassigned a diagnosis based on the ICD-9 criteria (World Health Organization, 1978). In keeping with European diagnostic practice, the diagnosis of hyperkinetic syndrome (HS) was applied only when there was evidence of clinically significant hyperactivity on both parental and teacher reports (Taylor, 1986). The criteria for clinically significant hyperactivity on each of these measures were similar to those used to establish DSM-III diagnosis. Criteria for ICD-9 diagnoses of LD, ED, and CD were the same as DSM-III criteria except that CD was not diagnosed if the child's oppositional behavior was limited to his relationship with a parent.

Hyperactive behavior during testing was rated by the experimenter using a subset of items from the Rutter-Graham Interview Questionnaire (Rutter \& Graham, 1968). A rating between 0 and 4 was made for each of overactivity, fidgetiness, inattentiveness, and distractibility. The total score was used as a measure of hyperactivity during attention testing so that the effect of these behaviors on performance could be assessed.

\section{Apparatus and Stimulus}

Stimuli were presented on an Apple IIE computer, and response times were collected using the Digitry Cognitive Testing Station response box and timing software. Subjects were seated about 16 inches from the computer 
screen, with a Schmidt trigger response key positioned directly in front of them. Stimuli were single letters displayed in the center of the screen for 500 milliseconds. One letter appeared every 2 seconds.

Depending on the version, target letters were the letter $\mathrm{A}$, the letter $\mathrm{A}$ when directly preceded by an $\mathrm{A}$, or the letter $\mathrm{X}$ when immediately preceded by the letter $A$. The target letter appeared on $10 \%$ of the trials in each version. In the AA version, the letter A appeared alone on $10 \%$ of trials, and in the $\mathrm{AX}$ version, the letter $\mathrm{X}$ appeared without an immediately preceding $\mathrm{A}$ on $10 \%$ of trials. Two types of false alarms were recorded: responses to the warning letters and responses to all other nontarget letters. Nontarget letters were randomly chosen from the pool of consonants $(\mathrm{F}, \mathrm{G}, \mathrm{H}, \mathrm{J}, \mathrm{K}, \mathrm{T}, \mathrm{V}, \mathrm{B}$, $\mathrm{N}$ ) and occurred with equal frequency within each block of 30 trials. For each version, 300 trials were presented to each child.

\section{Procedure}

After an initial period with his family and a child psychiatrist, the child was taken to a nearby testing room for the psychoeducational and attentional testing. Each child was tested individually and was instructed to watch the screen and press the response key whenever he detected a target letter. The child was told to press as quickly as possible without making mistakes. On occasion, he was told to "stick to it" or "keep going" if he asked to stop the task. All children finished the task, even though some commented about fatigue or boredom. Total length of time on task for the three versions was about 45 minutes, with a short break between versions. Order of presentation of the three versions was counterbalanced over the subjects.

\section{Design}

The study employed a $6 \times 3 \times 2$ factorial design with repeated measures for CPT version (A, AX, AA) and time (first or second half of the trials). The percentages of correct detections (hits) and false alarms, and the response time for correct target detections of each subject were compared. Hits and response times are direct indices of attention to task. False alarms indicate that the subject has responded on insufficient information. Therefore, it is an index of both attention to task (i.e., inattentiveness results in the subject's accumulating insufficient information about the target) and response style (i.e., impulsiveness). An interaction between diagnostic group and time on task, version of the CPT, or type of false alarm (on the $\mathrm{AA}$ and $\mathrm{AX}$ versions) indicates an attention deficit. 
Planned comparisons were conducted to detect differences in the performance of (a) hyperactive and normal children, (b) all pathological control groups together and normal children, and (c) the hyperactive group and all pathological control groups.

\section{RESULTS}

The characteristics of each DSM-III and ICD-9 diagnostic group are shown in Table I. Mean age, full-scale IQ, and ratings of activity during attentional testing did not differ significantly among diagnostic groups regardless of the classification system used. Some children had ED or LD in addition to their primary diagnosis. An additional diagnosis of ED did not occur significantly more often in the $\mathrm{CD}$, Mixed CD + ADDH, or ADDH groups $\left(\chi^{2}(2)=2.5\right.$, n.s.), and the rate of an additional diagnosis of LD did not differ among ED, $\mathrm{CD}$, Mixed ADDH $+\mathrm{CD}$, and ADDH groups $\left(\chi^{2}(3)\right.$ $=7.0$, n.s.). Thirty-two children were assigned to one diagnostic group by DSM-III criteria and to another group by ICD-9 criteria. In 15 of these cases, the change was from Mixed $C D+A D D H$ to $C D$. In an additional 10 subjects, the diagnosis shifted from ADDH to one not involving hyperactivity. This means that these subjects presented with situation-specific (i.e., at home or at school only) hyperactivity. Seven CD cases were reassigned to LD or ED diagnoses because their oppositional behavior, although marked, was limited to the relationship with their parents. Four subjects, who presented with situation-specific hyperactivity only, could not be assigned an ICD-9 diagnosis but did receive a DSM-III diagnosis of ADDH.

As predicted, performance deteriorated with time on task. With increasing time, the subjects had slower response times $(F(1,108)=31.04, p$ $<.01)$ and fewer correct detections $(F(1,108)=21.98, p<.01)$ on all three versions. Performance (with percent correct detections as the criterion) deteriorated on the AX and AA versions more than on the A version $(F(2,216)=4.24, p<.05)$, as indicated by a significant interaction between version and time.

Also as predicted, significant differences in performance were found among the three CPT versions (Tables II-IV). The versions differed for mean response time $(F(2,216)=78.64, p<.01)$. Response time to correct detections was fastest for the AX version and slowest for the A version (AX $=577$ milliseconds, $\mathrm{AA}=608$ milliseconds, $\mathrm{A}=720$ milliseconds). Fewer correct targets were detected on the AA and AX versions $(93.1 \%$ and $93.6 \%$, respectively) than on the A verison $(94.5 \%)$, but the differences were not significant $(F(2,216)=1.98$, n.s. $)$. Overall, the false alarm rate varied significantly among versions $(F(2,216)=30.35, p<.01)$. More 


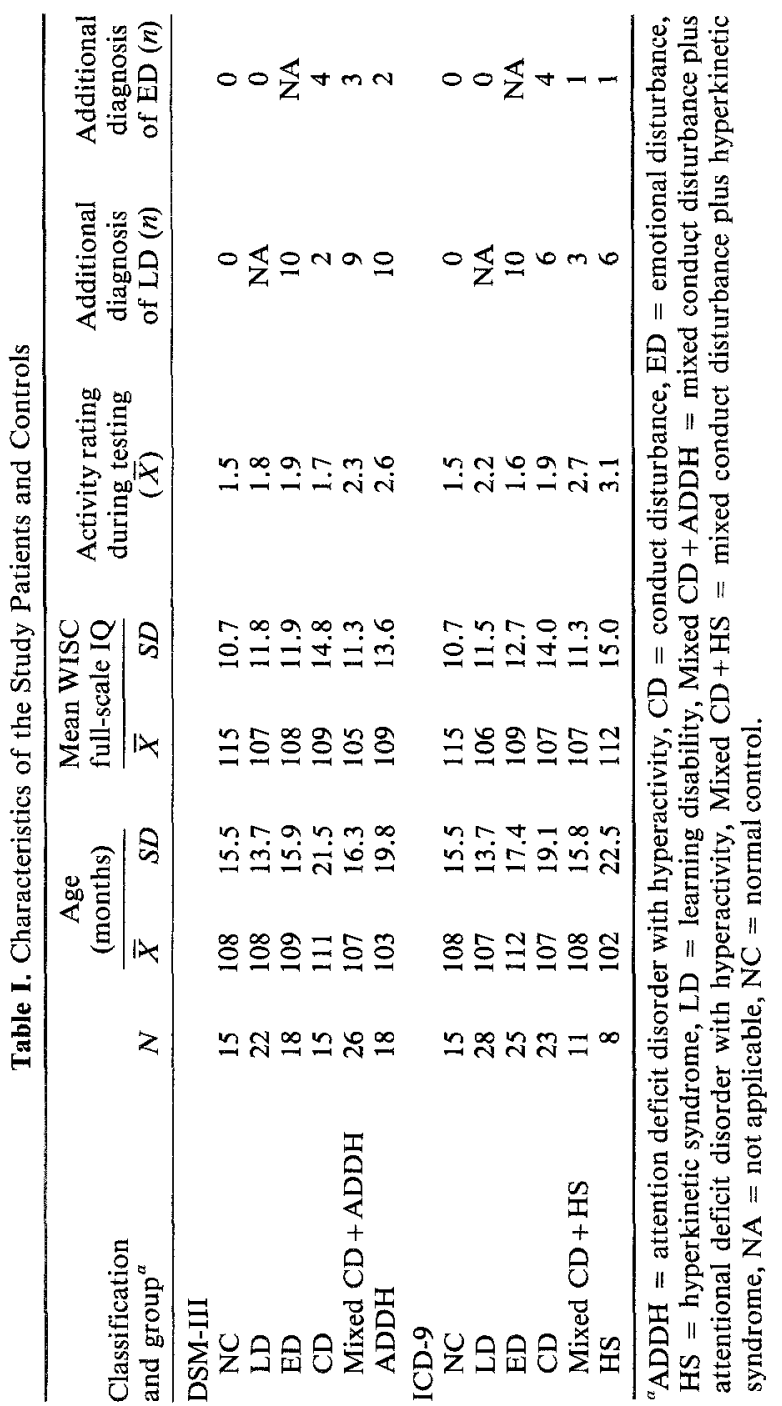


Table II. Response Time for Each Version of the CPT, by Diagnostic Group

\begin{tabular}{|c|c|c|c|c|c|c|}
\hline \multirow[b]{3}{*}{ Group $^{a}$} & \multicolumn{6}{|c|}{ CPT version } \\
\hline & \multicolumn{2}{|c|}{ A } & \multicolumn{2}{|c|}{ AA } & \multicolumn{2}{|c|}{$\mathrm{AX}$} \\
\hline & $\bar{X}$ & $S D$ & $\bar{X}$ & $S D$ & $\bar{X}$ & $S D$ \\
\hline \multicolumn{7}{|l|}{ DSM-III } \\
\hline $\mathrm{NC}$ & 697 & 183 & 643 & 210 & 568 & 169 \\
\hline LD & 720 & 124 & 592 & 154 & 585 & 148 \\
\hline ED & 722 & 165 & 622 & 191 & 597 & 165 \\
\hline $\mathrm{CD}$ & 760 & 165 & 634 & 250 & 585 & 215 \\
\hline Mixed CD + ADDH & 706 & 140 & 593 & 147 & 552 & 130 \\
\hline $\mathrm{ADDH}$ & 725 & 154 & 582 & 125 & 581 & 111 \\
\hline \multicolumn{7}{|l|}{ ICD-9 } \\
\hline NC & 697 & 183 & 643 & 210 & 568 & 169 \\
\hline LD & 722 & 129 & 605 & 161 & 588 & 150 \\
\hline ED & 703 & 166 & 581 & 183 & 576 & 159 \\
\hline $\mathrm{CD}$ & 710 & 149 & 596 & 169 & 548 & 123 \\
\hline Mixed $C D+H S$ & 747 & 142 & 637 & 121 & 580 & 112 \\
\hline HS & 746 & 114 & 578 & 85 & 584 & 83 \\
\hline
\end{tabular}

${ }^{a} \mathrm{ADDH}=$ attention deficit disorder with hyperactivity, $\mathrm{CD}=$ conduct disturbance, $\mathrm{ED}=$ emotional disturbance, $\mathrm{HS}=$ hyperkinetic syndrome, $\mathrm{LD}=$ learning disability, Mixed CD + ADDH $=$ mixed conduct disturbance plus attentional deficit disorder with hyperactivity, Mixed CD $+\mathrm{HS}$ $=$ mixed conduct disturbance plus hyperkinetic syndrome, $\mathrm{NC}=$ normal control.

false alarms of all types were made on the AA version than on the AX or A version $(1.6 \%, 1.1 \%$, and $0.5 \%$, respectively).

When performance on the AA and AX versions was compared, an interaction between type of false alarm and version was evident $(F(1,108)=$ $65.1, p<.01$ ). This finding indicates that more false alarms were made to the warning A's $(1.5 \%)$ than to other nontarget letters $(0.7 \%)$, and that these warning-signal false alarms were more common in the AA (2.3\%) than the $\mathrm{AX}(0.7 \%)$ version.

Children in each group were equally affected by the demand for sustained attention imposed by increasing time on task, as was indicated by the absence of significant interactions between time and diagnostic group or between time, version, and group. In addition, planned comparisons indicated no difference between ADDH and NC for response times, hits, or false alarms.

Therefore, data were analyzed without time as a factor, to assess the relationship of CPT versions and diagnostic grouping to performance. Once again, no interaction was found between DSM-III diagnosis and CPT version for response times, hits, or false alarms. 
Table III. Percentage of False Alarms for Each Version of the CPT, by Diagnostic Group

\begin{tabular}{|c|c|c|c|c|c|c|}
\hline \multirow[b]{3}{*}{ Group $^{a}$} & \multicolumn{6}{|c|}{ CPT version } \\
\hline & \multicolumn{2}{|c|}{ A } & \multicolumn{2}{|c|}{ AA } & \multicolumn{2}{|c|}{$\mathrm{AX}$} \\
\hline & $\bar{X}$ & $S D$ & $\bar{X}$ & $S D$ & $\bar{X}$ & $S D$ \\
\hline \multicolumn{7}{|l|}{ DSM-III } \\
\hline $\mathrm{NC}$ & 0.5 & 1.1 & 1.7 & 2.4 & 0.9 & 1.3 \\
\hline LD & 0.3 & 0.6 & 1.4 & 0.8 & 0.8 & 0.5 \\
\hline ED & 0.5 & 0.7 & 1.6 & 1.1 & 0.7 & 0.6 \\
\hline $\mathrm{CD}$ & 0.1 & 0.4 & 1.3 & 1.1 & 1.1 & 0.9 \\
\hline Mixed CD + ADDH & 1.0 & 1.3 & 1.8 & 1.5 & 1.6 & 1.8 \\
\hline ADDH & 0.6 & 0.7 & 1.6 & 2.1 & 1.1 & 1.2 \\
\hline \multicolumn{7}{|l|}{ ICD-9 } \\
\hline NC & 0.5 & 1.1 & 1.7 & 2.4 & 0.9 & 1.3 \\
\hline LD & 0.3 & 0.5 & 1.4 & 0.8 & 1.1 & 1.4 \\
\hline ED & 0.5 & 0.7 & 1.4 & 1.0 & 0.7 & 0.7 \\
\hline $\mathrm{CD}$ & 0.5 & 0.9 & 1.5 & 1.4 & 1.3 & 1.3 \\
\hline Mixed CD + HS & 1.1 & 1.8 & 1.8 & 1.3 & 1.1 & 0.5 \\
\hline HS & 1.0 & 0.8 & 2.1 & 2.9 & 1.8 & 1.5 \\
\hline
\end{tabular}

${ }^{a} \mathrm{ADDH}=$ attention deficit disorder with hyperactivity, $\mathrm{CD}=$ conduct disturbance, $\mathrm{ED}=$ emotional disturbance, $\mathrm{HS}=$ hyperkinetic syndrome, $\mathrm{LD}=$ learning disability, Mixed CD + ADDH = mixed conduct disturbance plus attentional deficit disorder with hyperactivity, Mixed $\mathrm{CD}+\mathrm{HS}$ $=$ mixed conduct disturbance plus hyperkinetic syndrome, $\mathrm{NC}=$ normal control.

To determine whether RT variability differed among the diagnostic groups, the mean of the standard of deviation of the groups was compared across the 3 CPT versions. Overall variability did not differ with group $(F(5,108)=0.78$, n.s. $)$, nor was group variability affected differently by the CPT versions $(F(10,216)=1.42$, n.s. $)$.

Comparison of performance on the $\mathrm{AA}$ and $\mathrm{AX}$ versions showed that the three-way interaction between type of false alarm, CPT version, and DSM-III diagnostic group was not significant $(F(5,108)=2.05$, n.s.). However, planned comparisons indicated that the three-way interaction was significant when children with ADDH were compared with normal controls $(F(1,108)=5.04, p<.05)$ and when all pathological groups together were compared with normal controls $(F(1,108)=6.67, p<.05)$, but not when the ADDH group was compared with all other pathological controls $(F(1$, $108)=.11$, n.s.). For both warning (Figure 1) and nontarget letters (Figure 2) the false alarm rate of normal controls did not vary between the AA and AX versions. The ADDH and pathological control groups made considerably more false alarms to the warning letter on the AA version than on the AX version. 
Table IV. Percentage of Hits for Each Version of the CPT, by Diagnostic Group

\begin{tabular}{|c|c|c|c|c|c|c|}
\hline \multirow[b]{3}{*}{ Group $^{a}$} & \multicolumn{6}{|c|}{ CPT version } \\
\hline & \multicolumn{2}{|c|}{ A } & \multicolumn{2}{|c|}{ AA } & \multicolumn{2}{|c|}{$\mathrm{AX}$} \\
\hline & $\bar{X}$ & $S D$ & $\bar{X}$ & $S D$ & $\overline{\bar{X}}$ & $S D$ \\
\hline \multicolumn{7}{|l|}{ DSM-III } \\
\hline NC & 93 & 10.3 & 94 & 7.4 & 95 & 6.0 \\
\hline LD & 94 & 11.5 & 90 & 8.6 & 93 & 8.1 \\
\hline ED & 98 & 3.8 & 94 & 6.7 & 95 & 6.5 \\
\hline $\mathrm{CD}$ & 95 & 5.7 & 92 & 7.7 & 92 & 8.5 \\
\hline Mixed CD + ADDH & 95 & 7.3 & 95 & 5.2 & 94 & 5.8 \\
\hline ADDH & 92 & 9.6 & 93 & 8.2 & 91 & 9.5 \\
\hline \multicolumn{7}{|l|}{ ICD-9 } \\
\hline NC & 93 & 10.3 & 94 & 7.4 & 95 & 6.0 \\
\hline LD & 94 & 11.0 & 91 & 8.2 & 93 & 8.5 \\
\hline ED & 98 & 3.4 & 94 & 7.2 & 95 & 6.4 \\
\hline $\mathrm{CD}$ & 95 & 5.8 & 94 & 6.4 & 92 & 7.4 \\
\hline Mixed $\mathrm{CD}+\mathrm{HS}$ & 93 & 8.5 & 94 & 6.2 & 96 & 4.6 \\
\hline HS & 91 & 11.7 & 94 & 5.4 & 90 & 10.2 \\
\hline
\end{tabular}

${ }^{a} \mathrm{ADDH}=$ attention deficit disorder with hyperactivity, $\mathrm{CD}=$ conduct disturbance, $\mathrm{ED}=$ emotional disturbance, $\mathrm{HS}=$ hyperkinetic syndrome, LD $=$ learning disability, Mixed CD + ADDH $=$ mixed conduct disturbance plus attentional deficit disorder with hyperactivity, Mixed CD + HS $=$ mixed conduct disturbance plus hyperkinetic syndrome, $\mathrm{NC}=$ normal control.

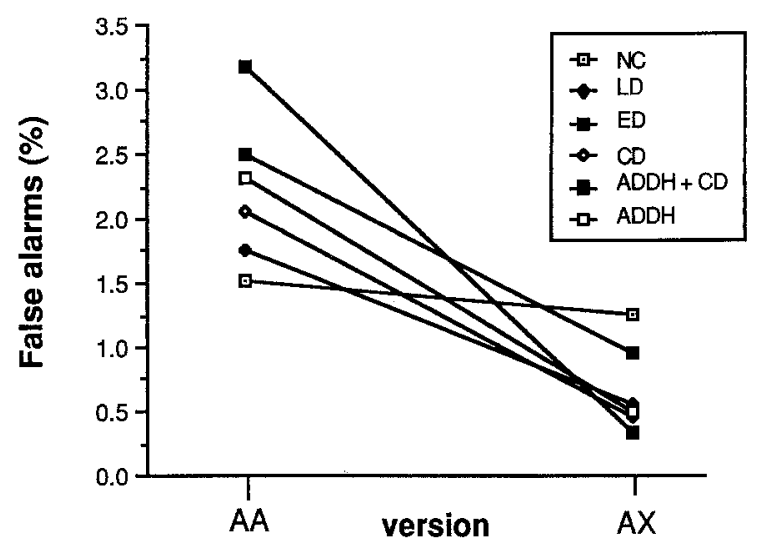

Fig. 1. False alarms (\% of trials) to the warning letters, by version and DSM-III diagnostic group. 


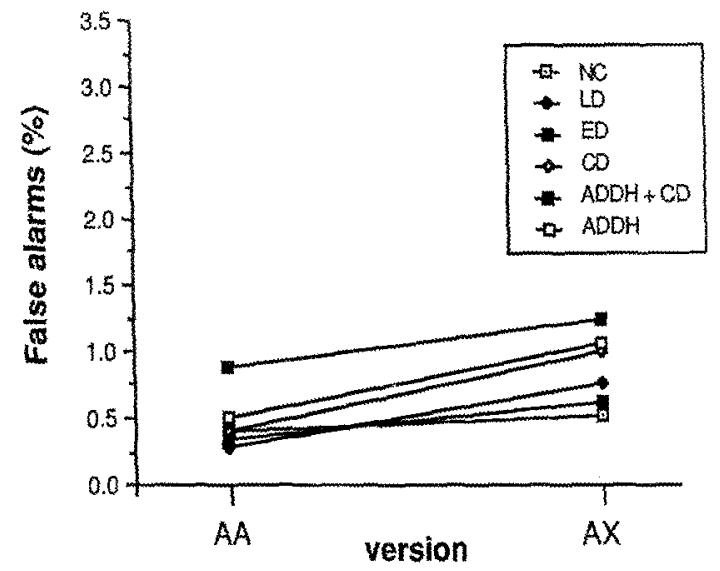

Fig. 2. False alarms (\% of trials) to nontarget letters, by version and DSM-III diagnostic group.

The results for ICD-9 diagnostic groups were similar. There was no evidence of an attention deficit, defined as an interaction between diagnostic group and CPT version for response times, hits, or false alarms.

When performance on the AA and $\mathrm{AX}$ versions was compared, a significant three-way interaction between ICD-9 diagnostic group, type of false alarm, and CPT version was found, suggesting that the diagnostic groups varied in impulsiveness $(F(5,104)=3.00, p<.05)$ (Figures 3 and 4 ). However, planned comparisons showed that the HS group did not differ

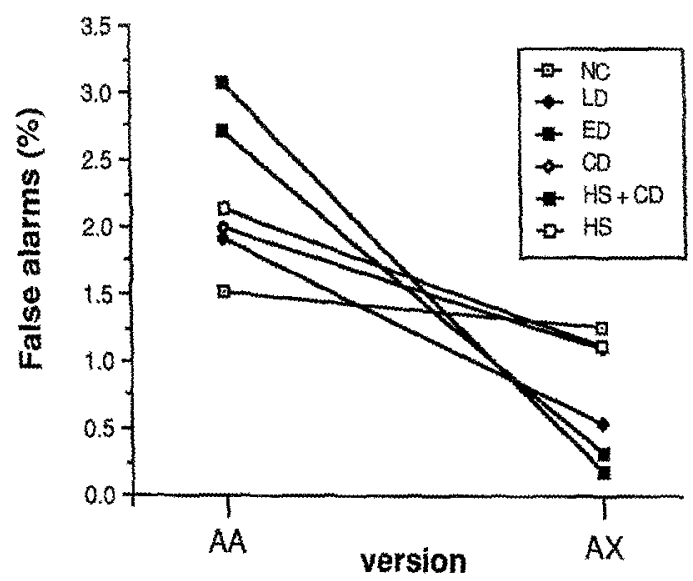

Fig. 3. False alarms (0 of trials) to the warning letters, by version and ICD -9 diagnostic group. 


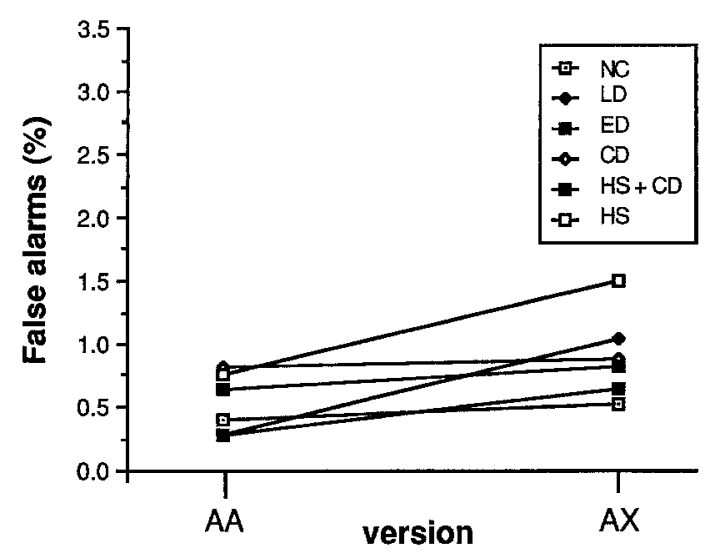

Fig. 4. False alarms (\% of trials) to nontarget letters, by version and ICD-9 diagnostic group.

significantly from the normal control group, whereas the pathological control groups together were different from the normal group $(F(1,104)=$ $6.19, p<.03)$. In particular, the Mixed CD + HS and the ED groups made more false alarms to the warning $\mathrm{A}$ in the AA version than in the AX version (Figure 3).

There were no significant main effects attributable to diagnostic group membership for either DSM-III or ICD-9 diagnoses.

Neither IQ nor ratings of activity during testing were significantly correlated with performance on the CPT. However, there was a significant correlation between age and $\mathrm{CPT}$ performance for reaction time $(\mathrm{A},-.52$; $\mathrm{AA},-.39 ; \mathrm{AX},-.36)$ and percent correct $(\mathrm{A}, .34 ; \mathrm{AX}, .45)$. For this reason, the effect of age on the association of diagnostic group and performance was checked. A repeated-measures analysis of variance was conducted, with diagnostic group as between-subject variable, performance measures for the CPT (response times, hits, false alarms) as within-subject factors, and age as a covariate. The patterns of significance in this analysis were the same as those in the previous analyses.

To determine whether the presence of LD was obscuring an association of attention and diagnosis, several additional analyses were conducted. All of the children with LD were omitted from the ED, CD, Mixed ADDH $+\mathrm{CD}$, and ADDH groups, and the groups were compared. No main effects for diagnosis or interactions between diagnosis and CPT version were found. The entire sample was then divided into those with LD and those without. No main effects or interaction between $L D$ and CPT version were evident. 


\section{DISCUSSION}

Our attentional manipulations were successful: Subjects had difficulty sustaining attention for the duration of the task, as evidenced by lower accuracy and longer reaction times in the second half of the trials. Subjects also showed an effect of preparation, evidenced by faster reaction times in the AA and AX versions than in the A version. There was some evidence of a speed/accuracy trade-off in the preparation effect, in that false alarm rates were higher in the AA and AX versions than in the A version. Such trade-offs are sometimes observed in studies of preparation (e.g., Posner et al., 1973; but see Thomas, 1974).

The time-on-task effect was stronger in the AA and AX versions than in the A version. This may reflect the fact that performance can deteriorate in more ways on the AA and AX versions, where subjects must sustain their attention in anticipation of the warning letter. If they detect the warning letter, they will be prepared for the target letter and the response time will be shorter. However, if they fail to detect the warning letter, they will lose the benefit of the preparation. In addition, they might not know whether a subsequent letter $\mathrm{A}$ or $\mathrm{X}$ is a target or a nontarget letter and will be forced to guess, producing a miss or a long response time. In contrast, in the A version, subjects either detect or miss the target letter $\mathrm{A}$.

There was no evidence indicating that a hyperactive group could be distinguished in terms of a sustained attention deficit. All diagnostic groups, whether constituted by DSM-III or by ICD-9 criteria, were equally affected by the two manipulations of attentional demand - time on task and the opportunity to prepare for a target. There was no evidence that the various diagnostic groups traded speed for accuracy differently in response to the preparation. This negative result could not be explained by differences in age, IQ, or activity level during testing.

False alarms to the warning signal in the AA and AX versions indicate that impulsiveness might be more relevant to the distinction between disturbed and normal children than is a deficit in sustained attention. It might partly explain the poor performance on some tasks by children with ADDH. However, it was not unique to this diagnosis. All pathological comparison groups differed from the normal controls in impulsiveness. In particular, the impulsiveness of children with ED was indicated by their greater number of false alarms to the warning signal in the AA than in the AX version. This finding demonstrates that emotional factors such as performance anxiety as well as cognitive factors can lead to impulsive performance.

When patients were rediagnosed using ICD-9 criteria, the HS group could not be distinguished from normal controls. Instead, the Mixed HS + $\mathrm{CD}$ and the ED groups showed the greatest increase in response to the warn- 
ing $\mathrm{A}$ in the $\mathrm{AA}$ version over the $\mathrm{AX}$ version. Therefore, our study has not succeeded in validating ADDH in terms of cognitive inattentiveness. In this regard, neither diagnostic system was demonstrably superior.

It might be possible to detect a deficit if a longer test were used. However, Sergeant (personal communication, 1984) has tested children on a longer task and found no evidence that would support this hypothesis. Also, failure to find any deficit in the preparation effect might indicate that this effect had reached an asymptote at the interstimulus interval of 2 seconds used in this experiment. Typically, in normal adults, preparation reaches asymptote at a 500-millisecond preparatory interval (Posner \& Boies 1971; Thomas, 1974). This study should be repeated with shorter preparatory intervals in order to be certain that there is no deficit in hyperactive children.

Our results do not confirm previous research demonstrating that hyperactive children show lower rates of overall accuracy on the CPT than normal children (Michael et al., 1981), since there was no main effect of group. This raises the possibility that the task was too easy to challenge the attentiveness of the subjects. However, differences between CPT versions and diagnostic groups were found. Furthermore, evidence of a main effect is not as relevant to the question of an attention deficit as is the presence of an interaction between diagnostic group and attention variable.

We have confidence in our results because the study was designed to correct several of the limitations of previous research. Diagnosis was based on careful assessment of child behavior in various settings, and hyperactivity was distinguished from conduct disorder. Furthermore, patients were diagnosed according to both of the commonly employed diagnostic schemata. Hyperactive children were compared with normal and with nonhyperactive, disordered control groups in order to determine whether inattentiveness was unique to hyperactivity. The presence of an interaction between the different attention demands imposed by these factors and diagnostic group membership was needed as evidence for an attention deficit. Rather than measuring either speed or accuracy, task performance was characterized in terms of both, to assess the possiblity that subjects traded speed for accuracy in different ways.

The failure to demonstrate a specific attentional correlate of ADDH confirms previous studies (Koriath, Gualtieri, Van Bourgondien, Quade, \& Werry, 1985; Werry et al., 1987) and underscores the need to compare hyperactive with nonhyperactive, disturbed children to control for the nonspecific correlates of psychopathology. While a deficit in sustained attention does not appear to distinguish hyperactive from normal or disturbed children, this study does not preclude the possibility that hyperactive children have deficits in other aspects of attention. Other factorial designs 
might detect the presence of deficits in impulsiveness, time-sharing capacity, or the ability to focus attention. It is clear from research that attention is neither a unitary phenomenon nor one that is independent of the circumstances in which it is measured (Parasuraman, 1983).

\section{REFERENCES}

American Psychiatric Association. (1980). Diagnostic and statistical manual of mental disorders (3rd ed.). Washington, D.C.: Author.

Anderson, J. C., Williams, S., McGee, R., \& Silva, P. A. (1987). DSM-III disorders in preadolescent children: Prevalence in a large sample from the general population. Archives of General Psychiatry, 44, 69-76.

Campbell, S. B. (1974). Cognitive styles and behavior problems of clinic boys: A comparison of epileptic, hyperactive, learning-disabled, and normal groups. Journal of Abnormal Child Psychology, 2, 307-312.

Ceci, S. J., \& Tishman, J. (1984). Hyperactivity and incidental memory: Evidence for attentional diffusion. Child Development, 55, 2192-2203.

Cohen, N. J., \& Douglas, V. I. (1972). Characteristics of the orienting response in hyperactive and normal children. Psychophysiology, 9, 238-245.

Conners, C. K. (1973). Rating scales in drug studies with children, Psychopharmacology Bulletin (Special Issue, Pharmacology of Children), pp. 24-29.

Douglas, V. I. (1983). Attentional and cognitive problems. In M. Rutter (Ed.), Developmental neuropsychiatry (pp. 280-329). New York: Guilford Press.

Firestone, P., \& Martin, J. E. (1979). An analysis of the hyperactive syndrome: A comparison of hyperactive, behavior problem, asthmatic, and normal children. Journal of $A b$ normal Child Psychology, 7, 261-273.

Goyette, C. H., Conners, C. K., \& Ulrich, R. F. (1978). Normative data on revised Conners Parent and Teacher Rating Scales. Journal of Abnormal Child Psychology, 6, 221-236.

Jastak, S., \& Wilkinson, G. S. (1984). The Wide Range Achievement Test Revised administration manual. Wilmington, Delaware: Jastak.

Koriath, U., Gualtieri, C. T., Van Bourgondien, M. E., Quade, D., \& Werry J. S., (1985). Construct validity of clinical diagnosis in pediatric psychiatry: Relationship among measures. Journal of the American Academy of Child Psychiatry, 24, 429-436.

Michael, R.L., Klorman, R., Salzman, L. F., Borgstedt, A. D., \& Dainer, K. B. (1981). Normalizing effects of methylphenidate on hyperactive children's vigilance performance and evoked potentials. Psychophysiology, 18, 665-677.

Nuechterlein, K. H. (1983). Signal detection in vigilance tasks and behavioral attributes among offspring of schizophrenic mothers and among hyperactive children. Journal of Abnormal Psychology, 92, 4-28.

Parasuraman, R. (1983). Vigilance, arousal and the brain. In A. Gale \& J. A. Edwards (Eds.), Physiological correlates of human behavior: Attention and performance (pp. 1-32). London: Academic Press.

Posner, M., \& Boies, J. (1971). Components of attention. Psychological Review, 78, 391-408.

Posner, M. I., Klein, R., Summers, J., \& Buggie, S. (1973). On the selection of signals. Memory and Cognition, 1, 2-12.

Quay, H. C. (1986). A critical analysis of DSM III as a taxonomy of psychopathology in childhood and adolescence. In T. Millon \& G. Klerman (Eds.), Contemporary direction in psychopathology: Towards DSM IV (pp. 151-165). New York: Guilford Press.

Rapoport, J. L., Buchsbaum, M. S., Weingartner, H., Zahn, T. P. Ludlow, C., \& Mikkelsen, E. J. (1980). Dextroamphetamine. Its cognitive and behavioral effects in normal and hyperactive boys and normal men. Archives of General Psychiatry, 37, 933-943. 
Rosvold, H. E., Mirsky, A. F., Sarason, I., Bransome, E. D., Jr., \& Beck, L. H. (1956). A continuous performance test of brain damage. Journal of Consulting Psychology, 20, 343-350.

Rutter, M. (1967). A children's behaviour questionnaire for completion by teachers: Preliminary findings. Journal of Child Psychology and Psychiatry, 8, 1-11.

Rutter, M., \& Graham, P. (1968). The reliability and validity of the psychiatric assessment of the child: I. Interview with the child. British Journal of Psychiatry, 114, 563-579.

Rutter, M., Tizard, J., \& Whitmore, K. (1970). Education, health and behaviour: Psychological and medical study of childhood development, New York: Wiley.

Schachar, R., Rutter, M., \& Smith, A. (1981). The characteristics of situationally and pervasively hyperactive children: Implications for syndrome definition. Journal of Child Psychology and Psychiatry, 22, 375-392.

Seigel, L. S., \& Heaven, R. K., (1986). Categorization of learning disabilities. In S. J. Ceci (Ed.), Handbook of cognitive, social, neuropsychological aspects of learning disabilities (Vol. 1, pp. 95-121). Hillsdale, New Jersey: Erlbaum.

Sykes, D. H., Douglas, V. I., \& Morgenstern, G. (1973). Sustained attention in hyperactive children. Journal of Child Psychology and Psychiatry, 14, 213-220.

Sykes, D. H., Douglas, V. I., Weiss, G., \& Minde, K. K. (1971). Attention in hyperactive children and the effect of methylphenidate (Ritalin). Journal of Child Psychology and Psychiatry, 12, 129-139.

Taylor, E. A. (1986). Overactivity, hyperactivity and hyperkinesis: Problems and prevalence. In E. A. Taylor (Ed.), The overactive child (pp. 1-18). Oxford: Blackwell.

Thomas, E. A. C. (1974). The selectivity of preparation. Psychological Review, 81, 442-464.

Wechsler, D. (1974). Wechsler Intelligence Scale for Children: Manual (revised). New York: Psychological Corporation.

Werry, J. S., Methven, R. J., Fitzpatrick, J., \& Dixon, H. (1983). The interrater reliability of DSM-III in children. Journal of Abnormal Child Psychology, 11, 341-354.

Werry, J. S., Reeves, J. C., \& Elkind, G. S. (1987). Attention deficit, conduct, oppositional, and anxiety disorders in children: I. A review of research on differentiating characteristics. Journal of the American Academy of Child and Adolescent Psychiatry, 26, 133-143.

World Health Organization. (1978). Mental disorders: Glossary and guide to their classification in accordance with the ninth revision of the international classification of diseases. Geneva: Author. 